\title{
A importância do parto humanizado: uma revisão bibliográfica
}

\author{
The importance of humanized birth: a bibliographic review
}

\author{
La importancia del nacimiento humanizado: una revisión bibliográfica
}

\begin{abstract}
Daniela de Campos Cardoso ${ }^{1 *}$, Michele Dias Barbosa ${ }^{1}$, Nanci da Hora Mendes ${ }^{1}$, Andréia Pereira da Silva ${ }^{1}$, Nadja Queiros Bonfim ${ }^{1}$, Wallace dos Santos Pereira ${ }^{1}$, Érica da Silva Cruz ${ }^{1}$, Maria Jucilene da Silva Mota², Lorena de Jesus Santos², Maria Hilda Almeida Amorin².
\end{abstract}

\section{RESUMO}

Objetivo: Explanar o atendimento à parturiente quanto à humanização ao parto. Métodos: Revisão literatura realizada com 12 artigos pesquisados nas bases de dados: (Lilacs) Literatura Latino Americana e do Caribe em Ciências da Saúde, (BDENF) Bases de Dados em Enfermagem. Resultados: O Parto Humanizado visa atender as necessidades de cada parturiente de maneira acolhedora e com a efetivação das ações educativas de promoção e recuperação delas no período gestacional e puérperio. Sendo assim, os resultados apontam que os enfermeiros que atuam na assistência ao parto contribuem para uma recuperação mais acelerada das mulheres com ajuda do companheiro ou dos familiares. Considerações finais: Conclui-se que os enfermeiros que atuam na assistência ao parto humanizado trazem inúmeros benefícios na assistência prestada à mulher, como a redução das complicações inerentes ao tempo de internamentos, a criação do vínculo com a parturiente e sua família, por meio da escuta ativa, a identificação das necessidades de cada gestante e possibilitar um ambiente acolhedor propício para desenvolvimento do trabalho de parto.

Palavras-chave: Gestantes, Enfermagem, Parto humanizado.

\begin{abstract}
Objective: To explain the care to the parturient regarding the humanization of childbirth. Methods: Literature review with 12 articles searched in the databases: (Lilacs) Latin American and Caribbean Health Sciences Literature, (BDENF) Nursing Databases. Results: The Humanized Childbirth aims meet the needs of each parturient in a welcoming manner and with the implementation of educational actions for their promotion and recovery during the gestational and postpartum period. Thus, the results indicate that nurses who work in childbirth care contribute to a faster recovery of women with the help of their partner or family members. Final considerations: It is concluded that nurses who work in humanized delivery care bring numerous benefits in the care provided to women, such as the reduction of complications inherent to the length of hospitalization, the creation of a bond with the parturient and her family through active listening, identifying the needs of each pregnant woman and enabling a welcoming environment conducive to the development of labor.
\end{abstract}

Key words: Pregnant women, Nursing, Humanized childbirth.

\section{RESUMEN}

Objetivo: Explicar el cuidado a la parturienta con respecto a la humanización del parto. Métodos: Revisión de la literatura con 12 artículos buscados en las bases de datos: (Lilacs) Literatura de Ciencias de la Salud de América Latina y el Caribe, (BDENF) Bases de datos de enfermería.Resultados: El parto humanizado tienes como objetivo satisface las necesidades de cada parturienta de manera acogedora y con la

\footnotetext{
${ }^{1}$ Centro Universitário Jorge Amado (UNIJORGE), Salvador-Bahia.

*E-mail: danielacardosocampos@hotmail.com

2 Universidade Católica de Salvador (UCSAL). Salvador-Ba.

${ }_{3}^{3}$ Universidade Salgado de Oliveira (UNIVERSO). Salvador-Ba.
} 
implementación de acciones educativas para su promoción y recuperación durante el período de gestación y posparto. Por lo tanto, los resultados indican que las enfermeras que trabajan en el cuidado del parto contribuyen a una recuperación más rápida de las mujeres con la ayuda de su pareja o miembros de la familia. Consideraciones finales: Se concluye que las enfermeras que trabajan en la atención de parto humanizado aportan numerosos beneficios en la atención brindada a las mujeres, como la reducción de las complicaciones inherentes a la duración de la hospitalización, la creación de un vínculo con el parto y su familia a través de escucha activa, identificando las necesidades de cada mujer embarazada y permitiendo un ambiente acogedor propicio para el desarrollo del parto.

Palabras clave: Mujeres embarazadas, Enfermería, Parto humanizado

\section{INTRODUÇÃO}

O momento do nascimento é muito especial na vida de uma mulher, algo tão singelo, particular compartilhado com seus familiares e companheiro. As experiências vividas pelas mulheres agregaram muito sentido na cultura desse evento e contribuiu para evolução na área medicina (ARAÚJO SM, 2013).

Antigamente, os partos eram feitos pelas parteiras, comadres ou curandeiras graças ao respeito e a consideração que as pessoas depositavam no trabalho feito por elas. As parteiras tinham um vínculo de amizade com as pessoas da comunidade, fazia a programação do parto, também a promoção da saúde, orientava sobre a alimentação, aleitamento e davam suporte emocional tanto para as mulheres quanto para seus familiares (CAUS ECM, et al., 2012).

Para Winck DR e Bruggemanni OM (2012), o declínio da profissão de parteira impulsionou a aceitação da obstetrícia como qualificação profissional e específica. Dessa forma, durante o nascimento é necessário ter uma equipe multidisciplinar qualificada para atuar de maneira segura e livre intercorrências, é crucial a participação do médico especialista na área obstétrica para a realização do parto livre de possíveis riscos e complicações tanto para a saúde das mulheres como para os recém-nascidos.

No parto natural o bebê nasce por via vaginal, sem intervenções analgésicas e estimulantes artificias. Esse método tem como foco respeitar a necessidade e escolha da mulher. O Parto normal é feito via vaginal, sendo inicialmente espontâneo, mas em alguns casos se faz necessário uma episiotomia, que é uma incisão cirúrgica feita no períneo, além da realização da massagem de conforto, musicoterapia, o banho morno, a deambulação que contribuem para o desenvolvimento do trabalho de parto. ou outras intervenções que visem ajudar no processo do nascimento (SODRE TM, et al., 2010).

O mecanismo do parto passou fundamentar a importância da autonomia da mulher para escolher e participar do parto. As mulheres passaram a sentir-se com medo, inseguras para escolher e fazer acontecer seus anseios e vontades perante os procedimentos realizados pelos profissionais atuantes no processo do parto. Dessa maneira, é essencial a prestação da assistência com respeito a particularidade e individualidade de cada mulher (JAMAS MT, et al., 2013).

O Programa de Humanização do Pré-natal e Nascimento (PHPN) foi inserido no ano 2000 objetivando garantir a qualidade da assistência prestada iniciada desde as consultas pré-natal até o puérperio (MINISTÉRIO DA SAÚDE, 2002). O parto humanizado deve preencher alguns requisitos, dentre eles os seguintes direitos: da parturiente passar por no mínimo seis consultas de pré-natal, a ter seu acompanhante e de garantir sua vaga em um hospital no momento do parto. Dessa maneira, o parto humanizado está voltado para garantir a autonomia da mulher sobre a escolha do seu tipo de parto de acordo com o que ela julgar mais adequado e confortável para o nascimento do seu filho (VELHO MB, et al., 2012).

A humanização do parto envolve a participação de toda equipe multidisciplinar munida de conhecimento tecnico-científico, ética profissional, responsabilidade e respeito à mulher assistida ofertando um processo de parto e nascimento saudável e digno (OLIVEIRA JC e SOUZA MKB, 2013). O PHPN por meio de estudo científicos comprovou que a capacitação da equipe de saúde é de extrema importância para garantia da adesão da humanização durante assistência prestada as mulheres, além de estabelecer a relação de 
profissional-paciente onde facilitará o processo de educação em saúde para promoção, prevenção e recuperação da saúde e garantir a independência da mulher sobre seu corpo e procedimentos a ser submetidas (VELHO MB, et al., 2012).

A Rede Cegonha, instituída pelo Ministério da Saúde no contexto do Sistema Único de Saúde (SUS), incentivam a criação de uma rede que objetiva a garantia dos cuidados à mulher, o direito à assistência humanizada durante todo período pré-natal até a realização do nascimento de maneira segura que contribuirá para o desenvolvimento saudável da criança (BRASIL, 2011).

A humanização do parto é um tema muito discutido pois é grande importância para garantir uma boa prática assistencial com respeito aos princípios da integralidade e acolhendo a mulher de forma global e permitindo que o momento do parto uma experiência positiva na vida da mesma sem intervenções desnecessárias que podem trazer um trauma por resto da vida (GONÇALVES R, et al., 2011).

Nas rotinas hospitalares diversas vezes as mulheres ficam impossibilitada de expressar o seu desejo de escolha sobre as intervenções realizadas durante o parto, deixando de ser a estrela deste momento. Com o aparecimento da humanização que vem buscando a independência da mulher durante o momento do parto e assegurando seus direitos (PRATA KS, et al., 2013). Os órgãos de saúde por meio das portarias e decretos possibilitar a utilização da humanização na prática assistencial (WINCK DR e BRUGGEMANNI OM, 2010).

Durante o atendimento prestado a mulher é essencial a realização do acolhimento com empatia, uma abordagem humana com intuito de proporcionar segurança, conforto, com escuta ativa das suas possíveis queixas, preocupações, angustias e visando o esclarecimento dessas dúvidas, garantindo a responsabilidade na atuação profissional, empenho na solução dos problemas e na evolução da assistência prestada (FRELLO AT, et al., 2012).

A presença de um acompanhante é de grande importância durante o parto, a parturiente tem o direito de escolher a pessoa que deseja está ao seu lado nesse momento tão marcante da sua vida direito previsto em lei. $O$ processo de humanização do parto traz um grande benefício para o desenvolvimento desse momento, ajudando a parturiente ser mais participativa nas condutas que estão sendo feitas, portanto, auxiliará os profissionais de saúde realizarem os procedimentos durante o parto de forma mais tranquila (PRATA KS, et al., 2013).

Esta pesquisa procura demonstrar a importância do parto humanizado e como a assistência humanizada pode contribuir para o desenvolvimento do trabalho de parto. Diante do exposto, apresenta-se a questão norteadora do presente estudo: como o parto humanizado pode contribuir para o desenvolvimento do trabalho de parto? A relevância do estudo está em trazer para reflexões e debates do conceito de parto humanizado, apontando suas contribuições às parturientes. O estudo poderá propiciar uma melhor compreensão das representações e práticas da importância do parto humanizado, visando não só um melhor resultado na assistência em maternidades como também garantir a satisfação e proporcionar benefícios às suas parturientes. Diante disso, o presente estudo tem como objetivo explanar o atendimento à parturiente quanto à humanização ao parto.

\section{MÉTODOS}

Trata-se de um estudo de revisão de literatura, que visa demonstrar a importância do parto humanizado demonstrando assim, o conhecimento sobre este tema, alcançando elementos para analisá-lo.

As buscas foram realizadas nas bases eletrônicas do (LILACS) Literatura Latino Americana e do Caribe em Ciências da Saúde e (BDENF) Bases de Dados em Enfermagem. A coleta foi realizada separadamente em cada base de dados utilizando a associação dos seguintes descritores em ciências da saúde (DeCS): Gestantes, Enfermagem, Parto Humanizado. Dos descritores associados Gestantes, Enfermagem, Parto Huminizado resultaram em um total de 44 artigos. Sendo 22 da LILACS, 20 da BDENF. (Figura 1) 
Figura 1 - Fluxograma da pesquisa representando a busca de dados.

\begin{tabular}{l} 
Bases de Dados \\
LILACS \\
BDENF \\
\hline
\end{tabular}
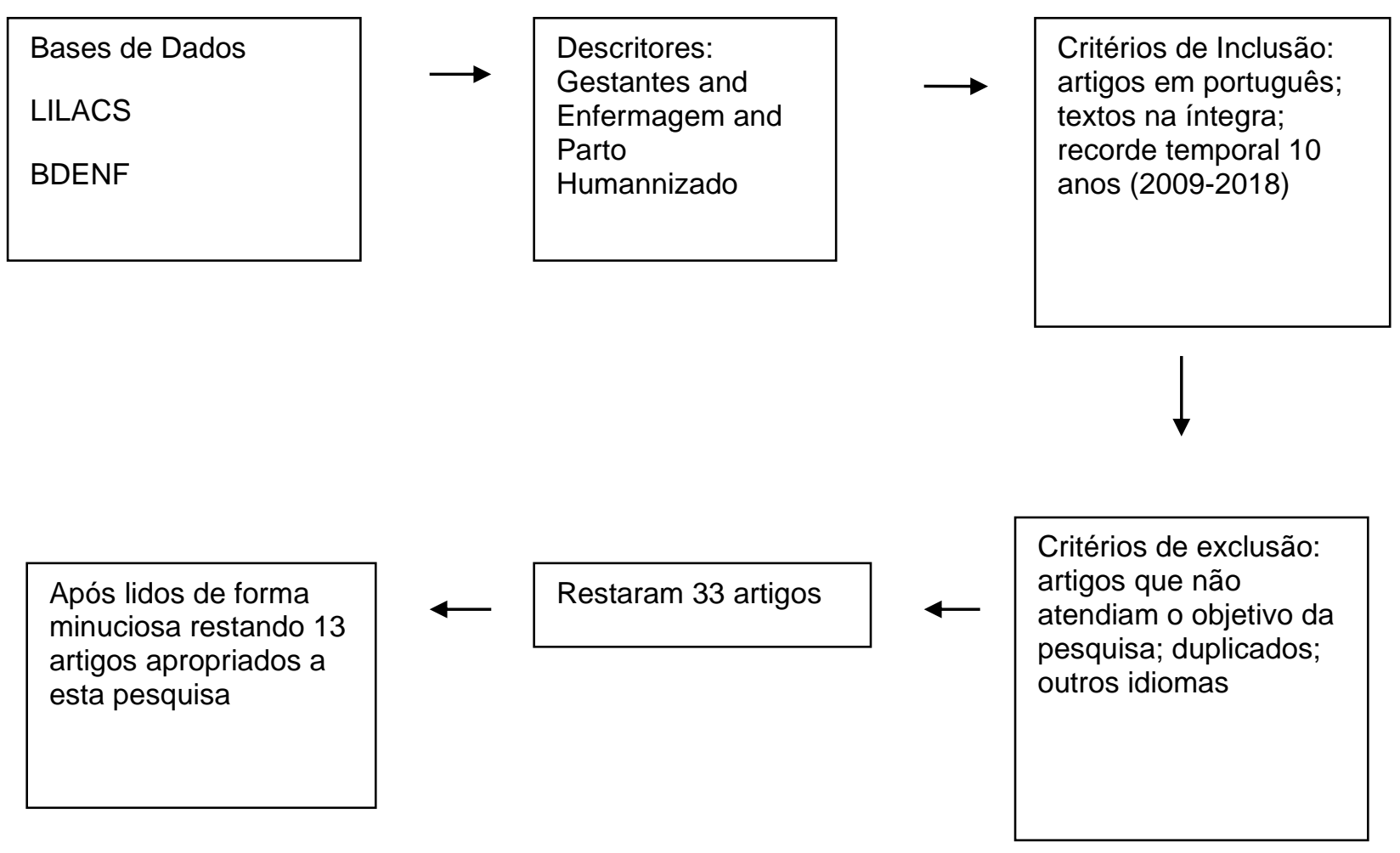

Fonte: Cardoso DA, et al, 2019.

\section{RESULTADOS}

Nesta revisão de literatura foram analisados 13 trabalhos relacionados ao objetivo da pesquisa. Para facilitar a apresentação e análise destes resultados, elaborou-se um quadro com os seguintes dados: autores/as, ano de publicação, título, objetivo da pesquisa (Quadro 1). 
Quadro 1 - Descrição dos artigos selecionados para o estudo.

\begin{tabular}{|c|c|c|c|c|}
\hline Autores/as & Ano de publicação & Título & Objetivo(s) & Conclusão \\
\hline $\begin{array}{l}\text { Mouta RJO } \\
\text { Progianti JM }\end{array}$ & 2009 & $\begin{array}{l}\text { Estratégias de luta das } \\
\text { enfermeiras da } \\
\text { maternidade Leila Diniz } \\
\text { para a implantação de } \\
\text { modelo humanizado de } \\
\text { assistência ao parto. }\end{array}$ & $\begin{array}{l}\text { Identificar as estratégias de luta } \\
\text { simbólica das enfermeiras da } \\
\text { Maternidade Leila Diniz para a } \\
\text { implantação de um modelo } \\
\text { humanizado de assistência ao } \\
\text { parto e analisar os efeitos da luta. }\end{array}$ & $\begin{array}{l}\text { Concluímos que as estratégias de luta desenvolvidas } \\
\text { por estes agentes contribuíram para que as enfermeiras } \\
\text { obstétricas conquistassem na maternidade posição } \\
\text { hierárquica para o desenvolvimento de práticas } \\
\text { obstétricas do modelo humanizado }\end{array}$ \\
\hline $\begin{array}{l}\text { Velasque } \\
\text { EAG, et al. }\end{array}$ & 2011 & $\begin{array}{l}\text { O Enfermeiro no processo } \\
\text { parir/nascer: Estratégia } \\
\text { de cuidado e } \\
\text { humanização do parto. }\end{array}$ & $\begin{array}{l}\text { Relatar vivências da prática } \\
\text { assistencial } \\
\text { desenvolvida junto às mulheres- } \\
\text { gestantes-parturientes, em um } \\
\text { município do interior do Rio } \\
\text { Grande do Sul. }\end{array}$ & $\begin{array}{l}\text { Conclui-se serem necessárias(os): a ampliação do } \\
\text { debate sobre a proposição da humanização, superando } \\
\text { resistências quanto a sua implantação; maior } \\
\text { visibilidade do papel do enfermeiro nesse processo; } \\
\text { arranjos intersetoriais na formação e atuação } \\
\text { profissional, pois repercutem na atenção às usuárias; } \\
\text { fomento à reflexão crítica de docentes, discentes, } \\
\text { profissionais e das mulheres sobre a urgente } \\
\text { modificação das práticas e saberes à atenção no } \\
\text { processo parir/nascer, ainda, vigentes no país. }\end{array}$ \\
\hline Frigo J, et al. & 2013 & $\begin{array}{l}\text { Assistência de } \\
\text { enfermagem a } \\
\text { perspectiva da mulher no } \\
\text { trabalho de parto e parto. }\end{array}$ & $\begin{array}{l}\text { Identificar as práticas da } \\
\text { assistência de enfermagem frente } \\
\text { ao trabalho de parto e parto em } \\
\text { hospital público e a perspectiva da } \\
\text { mulher neste processo. }\end{array}$ & $\begin{array}{l}\text { Verifica-se neste estudo que durante o parto os } \\
\text { sentimentos positivos se sobressaíram, oriundos das } \\
\text { mais variadas percepções; muitas gestantes relataram } \\
\text { que o alívio da dor no período do parto foi o motivo que } \\
\text { tornou maravilhoso esse momento, o que fez a dor } \\
\text { sentida ser menos importante que a vivência em ter o } \\
\text { filho nos braços. }\end{array}$ \\
\hline $\begin{array}{l}\text { Ferreira LA, } \\
\quad \text { et al. }\end{array}$ & 2013 & $\begin{array}{c}\text { Expectativa das gestantes } \\
\text { em relação ao parto. }\end{array}$ & $\begin{array}{l}\text { Descrever a expectativa das } \\
\text { gestantes em relação ao parto, } \\
\text { seus medos e anseios. }\end{array}$ & $\begin{array}{l}\text { Considera-se urgente a necessidade de que a } \\
\text { preparação para o parto se torne foco nos atendimentos } \\
\text { e serviços oferecidos no pré-natal, bem como nas } \\
\text { políticas públicas voltadas para essa área, a fim de } \\
\text { evitar os efeitos prejudiciais que o estresse, a } \\
\text { insegurança, o medo e outros fatores psicoemocionais e } \\
\text { ambientais possam ter nos momentos de trabalho de } \\
\text { parto e parto. }\end{array}$ \\
\hline
\end{tabular}




\section{Revista Eletrônica Acervo Saúde / Electronic Journal Collection Health ｜ ISSN 2178-2091}

\begin{tabular}{|c|c|c|c|c|}
\hline $\begin{array}{l}\text { Carvalho FV, } \\
\text { et al. }\end{array}$ & 2014 & $\begin{array}{l}\text { Direitos das parturientes: } \\
\text { conhecimento da } \\
\text { adolescente e } \\
\text { acompanhante }\end{array}$ & $\begin{array}{l}\text { Analisar o conhecimento de ado- } \\
\text { lescentes e seus acompanhantes } \\
\text { acerca dos seus direitos no parto }\end{array}$ & $\begin{array}{l}\text { Nesta pesquisa foi observado que, lamentavelmente, o } \\
\text { desconhecimento acerca dos direitos dos usuários dos } \\
\text { serviços de saúde, neste caso, do serviço de obstetrícia, } \\
\text { e a falta de informação e condições de cumprir as } \\
\text { diretrizes do Ministério da Saúde por parte da instituição } \\
\text { pesquisada ainda é uma realidade. }\end{array}$ \\
\hline $\begin{array}{l}\text { Versiane } \\
\text { CC, } \\
\text { et al. }\end{array}$ & 2015 & $\begin{array}{l}\text { Significado de parto } \\
\text { humanizado para } \\
\text { gestantes. }\end{array}$ & $\begin{array}{l}\text { Compreender o significado de parto } \\
\text { humanizado na concepção de } \\
\text { gestantes }\end{array}$ & $\begin{array}{l}\text { As gestantes definiram que o parto humanizado deve } \\
\text { ser pautado nas bases filosóficas da humanização do } \\
\text { parto e nascimento, preconizado pelo Ministério da } \\
\text { Saúde, que tem como princípios o relacionamento } \\
\text { interpessoal e uma assistência competente. Descritores: } \\
\text { Parto humanizado, Gestantes, Enfermagem obstétrica. }\end{array}$ \\
\hline $\begin{array}{l}\text { Francisco } \\
\text { BS, et al. }\end{array}$ & 2015 & $\begin{array}{l}\text { Percepções dos pais } \\
\text { sobre suas vivências } \\
\text { como acompanhantes } \\
\text { durante o parto e } \\
\text { nascimento. }\end{array}$ & $\begin{array}{l}\text { Conhecer quais as percepções do } \\
\text { pai acerca de sua vivência durante } \\
\text { o processo de nascimento do filho } \\
\text { no centro obstétrico de uma } \\
\text { maternidade pública de Santa } \\
\text { Catarina. }\end{array}$ & $\begin{array}{l}\text { Para os pais, estar com seu filho e sua mulher é um } \\
\text { momento singular, importante para fortalecer o vínculo e } \\
\text { dar apoio e suporte à mulher. Porém, o } \\
\text { desconhecimento acerca do processo de nascimento } \\
\text { gera sentimentos negativos e impotência no trabalho de } \\
\text { parto, que podem ser superados pelo compartilhamento } \\
\text { de conhecimentos entre enfermeiro e pais. Este estudo } \\
\text { amplia a produção de conhecimentos; dá voz aos pais, } \\
\text { subsidia o planejamento de ações dos profissionais. }\end{array}$ \\
\hline $\begin{array}{l}\text { Oliveira } \\
\text { JDG, et al. }\end{array}$ & 2016 & $\begin{array}{l}\text { Percepção de } \\
\text { enfermeiros obstetras na } \\
\text { assistência à parturiente. }\end{array}$ & $\begin{array}{l}\text { Conhecer a percepção do } \\
\text { enfermeiro obstetra na assistência } \\
\text { à parturiente. }\end{array}$ & $\begin{array}{l}\text { Nos discursos, os enfermeiros expressaram dificuldades } \\
\text { e facilidades na assistência à parturiente e percepção } \\
\text { da própria prática no setor de parto em seu papel bem } \\
\text { definido pela equipe, o que proporciona cuidados com } \\
\text { autonomia à parturiente. }\end{array}$ \\
\hline $\begin{array}{l}\text { Leas RE, } \\
\text { Cifuentes DJ }\end{array}$ & 2016 & $\begin{array}{l}\text { Parto humanizado: } \\
\text { Contribuições do } \\
\text { enfermeiro obstetra. }\end{array}$ & $\begin{array}{l}\text { Entender o trabalho de parto, a } \\
\text { compreensão sobre a dor e } \\
\text { percepção da dor, bem como a } \\
\text { caracterização do parto } \\
\text { humanizado. }\end{array}$ & $\begin{array}{l}\text { Compreendeu-se que o enfermeiro obstetra tem um } \\
\text { papel fundamental no parto e em sua humanização, } \\
\text { pois é o profissional capaz de acompanhar a parturiente } \\
\text { em todos os momentos e, dessa forma, deixá-la mais } \\
\text { segura, consciente dos procedimentos que serão } \\
\text { adotados e apta a participar das decisões sobre seu } \\
\text { corpo e o nascimento de seu filho. }\end{array}$ \\
\hline
\end{tabular}




\section{Revista Eletrônica Acervo Saúde / Electronic Journal Collection Health ｜ ISSN 2178-2091}

\begin{tabular}{|c|c|c|c|c|}
\hline $\begin{array}{l}\text { Barros TCX, } \\
\text { et al. }\end{array}$ & 2017 & $\begin{array}{c}\text { Assistência a mulher para } \\
\text { a humanização do parto e } \\
\text { nascimento. }\end{array}$ & $\begin{array}{c}\text { Analisar a assistência à mulher } \\
\text { para a humanização do parto e } \\
\text { nascimento. }\end{array}$ & $\begin{array}{l}\text { Apesar de inúmeros esforços para a implantação da } \\
\text { Humanização, ainda constitui uma grande causa a ser } \\
\text { mobilizada no país, pois há inúmeras práticas } \\
\text { promovidas na atenção ao parto e nascimento, } \\
\text { principalmente a episiotomia e a manobra de Kristeller. } \\
\text { Desse modo, o estudo contribui para como está sendo } \\
\text { realizada a assistência com as mulheres, focalizando os } \\
\text { princípios da humanização. Assim, faz-se necessários } \\
\text { estudos com o propósito de compreender o processo de } \\
\text { implantação da humanização. }\end{array}$ \\
\hline $\begin{array}{l}\text { Demarchi R, } \\
\text { et al. }\end{array}$ & 2017 & $\begin{array}{l}\text { Percepção de Gestantes } \\
\text { e puérperas primíparas } \\
\text { sobre a maternidade. }\end{array}$ & $\begin{array}{c}\text { Investigar a percepção de } \\
\text { gestantes e puérperas primíparas } \\
\text { sobre maternidade }\end{array}$ & $\begin{array}{l}\text { Foi possível compreender a vivência da mulher rumo ao } \\
\text { papel materno, seus sentimentos, realizações, } \\
\text { dificuldades, mudanças impostas pela chegada do bebê } \\
\text { e o cuidado de enfermagem nessa fase de transição. }\end{array}$ \\
\hline $\begin{array}{c}\text { Andrade LO, } \\
\text { et al. }\end{array}$ & 2017 & $\begin{array}{l}\text { Práticas dos profissionais } \\
\text { de enfermagem diante do } \\
\text { parto humanizado. }\end{array}$ & $\begin{array}{l}\text { Conhecer como são desenvolvidas } \\
\text { as práticas de humanização } \\
\text { durante o trabalho de parto }\end{array}$ & $\begin{array}{l}\text { Torna-se de fundamental importância o preparo da } \\
\text { parturiente para a proposta do parto humanizado desde } \\
\text { o pré-natal, com o emprego das práticas humanizadas } \\
\text { respaldado nas evidências científicas. }\end{array}$ \\
\hline Medeiros A. & 2018 & $\begin{array}{l}\text { A Casa de Parto David } \\
\text { Capistrano Filho pelas } \\
\text { lentes de uma fotógrafa }\end{array}$ & $\begin{array}{l}\text { Demonstrar o atendimento com } \\
\text { práticas não medicalizadas e } \\
\text { cuidado transdisciplinar. }\end{array}$ & $\begin{array}{l}\text { A Casa de Parto é um equipamento público de saúde } \\
\text { que atende a gestantes de baixo risco habitual em } \\
\text { Realengo, zona oeste do Rio de Janeiro. Sua proposta } \\
\text { mais ampla de saúde se baseia em educação e } \\
\text { informação por meio do acolhimento de proximidade e } \\
\text { vínculo, práticas não medicalizadas e cuidado } \\
\text { transdisciplinar. }\end{array}$ \\
\hline
\end{tabular}

Fonte: Cardoso DA, et al, 2019. 


\section{DISCUSSÃO}

O atendimento à parturiente com humanização durante parto é de extrema importância para assegurar as mulheres assistidas uma assistência de qualidade e livre de violências obstétricas que podem gerar um trauma futuro. A atuação do enfermeiro juntamente com a equipe muldisciplinar sem dúvidas tem um papel de grande relevância nesse processo de adesão do processo de humanização durante o parto (FERREIRA DJ, et al., 2015). Segundo Demarchl RF, et al., (2017) as principais alterações ocorridas no período gestacional vão além das mudanças gravídicas, o lado emocional é onde ocasionar a maior fragilidade nas mulheres, gerando a preocupação acerca da sua habilidade para lidar com o momento do parto e a espera do nascimento do seu filho.

Para Mouta RJ e Progianti JM (2009) na área obstétrica é importante que os enfermeiros atuantes na assistência de enfermagem ao parto executem suas atividades com humanização, além de ser importante que os enfermeiros tenham capacitação de enfermagem obstétrica (pós-graduação latu sensu), como o objetivo de adquirir preparo científico para atuar nas suas atividades com segurança, responsabilidade e garantir a qualidade assistencial. Durante o trabalho de parto (TP) é fundamental a garantia do cumprimento do direito ao acompanhante da escolha da mulher previsto pela lei, com o objetivo de acalmar à mulher e na diminuição da sua ansiedade e medo para conseguir participar desse processo de maneira ativa para auxiliar no desenvolvimento do parto (FRANSCISCO BS, et al., 2015).

Portanto, para Ferreira DJ, et al., (2013) é essencial que o enfermeiro ao realizar o atendimento as parturientes consigam estabelecer uma abordagem efetiva com mesma, com o intuito de identificar as suas preocupações e dúvidas em relação o TP e parto. Dessa forma, será possível realizar as implementações importante para solucionar essas dificuldades encontradas, além de possibilitar segurança e conforto acerca do momento do parto.

As mulheres durante o período gravídico enfrentam diversas fragilidades, marcado por turbilhões de sentimentos ocasionados pelas alterações hormonais, como o medo do trabalho de parto, dúvidas sobre o seu leite e o processo de amamentação, dos procecimentos que serão realizados durante o parto, daí a importância da atuação do enfermeiro visando o esclarecimento dessas dificuldades enfrentadas pelas mesmas (MOUTA RJ e PROGIANTI JM, 2009).

Para garantir que o processo do parto humanizado aconteça, é importante que a instituição de saúde tenha um local adequadamente preparado para isso. Para que todas as condutas realizadas pelos profissionais atuantes dentre elas a higienização, espaço adequado, luz na medida certa, possibilidade de realizar musicoterapia, banheira ou piscina para o nascimento, entre tantas outras sejam feitas com respeito e atenção (LEAS RE e CIFUENTES DJ, 2016).

A humanização do parto traz inúmeros benefícios para à mulher, como a garantia do respeito da autonomia, o direito da presença do acompanhante da sua escolha, práticas assistenciais seguras e acolhedoras, suporte emocional tanto para gestante como ao seu familiar, um ambiente propício para possibilitar um momento especial e auxiliar no desenvolvimento do trabalho de parto, além da diminuição dos sintomas apresentados durante o trabalho de parto como a dor que são controlados graças as intervenções adotadas pela equipe de multiprofissional atuante na saúde da mulher (CARVALHO VF, et al., 2014).

Os profissionais de saúde utilizam o seu conhecimento e sua experiência para a identificar os fatores sociais e culturais do parto e nascimento, visando que suas práticas assistenciais sejam realizadas de maneira efetiva, livre de práticas desnecessárias, além de utilizar a comunicação como ferramenta essencial para realizar a abordagem adequada objetivando a criação do vínculo com as mulheres e seus familiares esclarecimentos das dúvidas, sua agilidade e destreza e atenção é fundamental para a execução das suas atividades (DEMARCHI RF, et al., 2017).

A equipe multidisciplinar tem um papel muito importante no processo de humanização do parto, pois realizar o planejamento adequado para suprir as necessidades da mulher no momento do parto, tornando esse momento menos frustante, de forma a ser uma experiência de vida ao longo do seu processo de 
crescimento e desenvolvimento da mesma, é um grande desafio a ser alcançado por todos os profissionais atuantes na saúde da mulher (FRIGO J, et al., 2013). A atuação dos profissionais de saúde de forma a garantir a utilização das terapias não farmacológicas para diminuição das dores e auxiliar no desenvolvimebto do parto. Dessa maneira, é muito importante ações educativas iniciadas desde o período gestacional durante o acompanhamento pré-natal, os enfermeiros tanto da atenção básica ou hospitalar (FRANCISCO BS, et al., 2015).

Os enfermeiros obstetras durante as consultas de pré-natal devem realizar as atividades de promoção à saúde de forma acolhedora, especialmente, com as primíparas por não possuírem experiências negativas de outros partos. As parturientes ficam com sentimentos de angústias e com isto é fundamental os enfermeiros trabalharem a humanização através de medidas saudáveis, como a conversação, a deambulação, o banho morno, o incentivo da participação do companheiro para as mesmas sintam-se segura por meio da tranquilidade e paciência ofertados pelos enfermeiros atuantes (OLIVEIRA JD, et al., 2016).

Durante o processo de nascimento de seu filho no centro obstétrico, é necessárioa valorização da presença do pai durante trabalho de parto para vivenciar esse momento tão especial, caso não seja possível os profissionais de saúde devem ofertar todo apoio e suporte emocional para que as mulheres se sintam acolhidas e respeitadas. A realização do parto normal é um momento único para o casal, gerando muita alegria e concretização de um sonho. Dessa maneira, durante o momento do parto os pais ficam muito preocupados acerca de como proceder durante o trabalho de parto, com medo de gerar transtorno durante esse processo, daí a importância da atuação do enfermeiro para promover a orientação adequada sobre esses questionamentos (VELASQUE EAG, et al., 2011).

Para Carvalho VF et al., (2014) o enfermeiro tem que utilizar a comunicação como ferramenta facilitadora no processo do cuidado prestado. O cuidado humano é a melhor estratégia efetiva que a equipe de saúde e as famílias dispõem para ajudar as gestantes no momento do parto. Assim, tornar o momento do trabalho de parto menos traumático, de forma a ser como mais uma experiência de vida ao longo do seu processo de crescimento e desenvolvimento, é um grande desafio a ser realizado e alcançado por todos os profissionais de saúde.

No atendimento à parturiente é essencial que os cuidados prestados sejam de maneira humanizada, ofertando suporte emocional e fortalecendo o convívio paciente-profissional para facilitar o processo de trabalho de parto. $O$ trabalho em equipe multidisciplinar e interdisciplinar no atendimento ao parto visa a execução da integralidade em saúde no sentido de permitir uma atuação em saúde mais fundamentada e resolutiva.

Segundo Andrade LO, et al., (2017) o modelo de humanização é insubstituível no envolvimento da mulher e a equipe de saúde durante as práticas do cuidado e necessário o envolvimento e aderência do gestor de saúde à essa missão proposta.

Para Demarchi RF, et al (2017) no processo de maternidade vivenciado pelas mulheres, é marcado por diversas dúvidas, incertezas, sentimentos esses que ficam presente a todo instante e vai além do envolvimento mãe-filho, ficando evidente a importância presença da família nessa fase tão especial na vida de qualquer mulher. É crucial que o enfermeiro atuante na assistência das parturientes tenha a percepção de como a participação familiar traz inúmeros benefícios para a redução desses sentimentos presentes durante o período gestacional.

Para a realização do cuidado prestado as parturientes, a enfermeira tem como princípio proporcionar um ambiente confortável e tranquilo que auxilie no controle do seu estado emocional, além de permite a participação da mulher durante o TP. O nascimento de uma criança vai além de um procedimento técnico, é um momento especial e único que gera as futuras recordações positivas na vida de qualquer mulher (FRIGO J, et al., 2013). Durante o atendimento á parturiente, o enfermeiro deve ter um olhar global, buscando a identificação das necessidades, entender e encontrar uma maneira de solucionar aquela fragilidade encontrada na medida do possível. Saber reconhecer as diferenças culturais, religiosas e 
individuais sem dúvidas é o caminho que possibilitará uma assistência mais humanizada (VERSIANE CC, et al., 2015).

A humanização do parto e nascimento deve ser um modelo de atenção obstétrico a ser utilizado nas maternidades e ou unidade de saúde onde há assistência ao evento de nascimento, visando a garantia do direito da autonomia e empoderamento das mulheres a ter um parto humanizado e respeitoso onde atendam as suas expectativas e colaborando para extinção de práticas prejudiciais ao parto (BARROS TC, et al., 2017).

Segundo Frigo J, et al. (2013) as mulheres relatam o sentimento de algia durante o parto, daí a importância da avaliação da dor com respeito do limiar individual de cada mulher. Para as mulheres, o parto sempre foi marcado por algia e sofrimento é crucial acabar com essa percepção por meio de boas práticas dos profissionais atuantes na saúde da muher.

Os enfermeiros precisam ser treinados para a realização do modelo de humanização na assistência ao parto pois é um atendimento diferenciado, que objetiva a qualidade assistencial para as usuárias e garantir os resultados satisfatórios da assistência prestada. Desta maneira, as parturientes assistidas terão vivências positivas em um ambiente propício e ideal para chegada do seu filho livre de possíveis complicações por práticas inadequadas conhecidas como violência obstétrica (MOUTA RJ e PROGIANTI JM, 2009).

O enfermeiro tem como papel de educador em saúde estimulando as famílias das parturientes sobre a importância da sua participação durante todo período gestacional e puerpério. Desta maneira, fica evidente a necessidade da ajuda dos familiares ou companheiro nos cuidados ao recém-nascido com objetivo de evitar a sobrecarga de atividades realizadas pelas parturientes que podem levar ao desgaste físico e mental das mesmas e tem grande contribuição para o fortalecimento desse momento tão especial e único na vida do casal (DEMARCHI RF, et al., 2017).

O parto humanizado tem o envolvimento do respeito, dos cuidados bastante específicos e atenção direcionada à gestante, definindo a adesão de intervenções que auxilie a diminuição da algia, como a realização de massagens de conforto, banhos de chuveiro e banheira de hidromassagem, musicoterapia são técnicas voltadas para o relaxamento, de forma que a mulher desvie o foco da algia para o momento da chegada de seu filho, tornando o momento marcante e sem sofrimento (LEAS RE e CIFUENTES DJ, 2016).

A equipe deve estar capacitada para detectar os possíveis riscos habituais que são monitorados por meio das agendas de consultas, exames e da participação nas atividades educativas, incorporadas ao prénatal como parte do acompanhamento (MEDEIROS A, 2018).

Sabendo da contribuição do processo de humanização no parto no atendimento realizado pelo enfermeiro onde requer uma boa dinâmica entre os membros atuantes, onde não pode faltar atenção, responsabilidade, respeito, ética, os enfermeiros necessitam ter conhecimento científico, práticas na efetivação das suas atividades e precauções na realização dos procedimentos necessários. Através das análises dos estudos foram observados que os principais fatores que contribuem no atendimento humanizado durante o parto são: profissionais habilitados, boa comunicação, ambiente acolhedor, limpo e seguro com a presença do acompanhante, o respeito da independência da mulher. Sabendo que apesar da existência desses fatores é essencial que os enfermeiros sejam responsáveis para dar continuidade a realização das suas atividades sem causar transtornos na sua assistência garantindo a qualidade assistencial.

\section{CONSIDERAÇÕES FINAIS}

Acreditamos no processo de humanização no parto, como reestruturação da atenção na saúde da mulher, que conta com uma equipe multidisciplinar, compostas por profissionais competentes e habilitados para realização da assistência humanizada e eficiente, onde o enfermeiro obstetra realiza práticas de relaxamento no momento do parto e estimular a participação do acompanhante nesse processo. Além da realização de ações educativas durante o período gestacional e puerpério de promoção e recuperação à 
saúde. O propósito deste estudo foi sinalizar para os leitores por meio das informações, a importância do parto humanizado, relatando as principais medidas para a sua realização e os seus benefícios para as mulheres e seus familiares assistidos. Conclui-se que os enfermeiros que atuam no atendimento assistência ao parto trazem inúmeros benefícios no atendimento à mulher, como a redução do tempo de internamentos inerentes aos procedimentos desnecessários, o convívio com as mulheres e sua família, por meio da escuta ativa, a identificação das necessidades de cada mulher e permitir um ambiente acolhedor e um bom desenvolvimento do seu trabalho de parto com a presença do acompanhante de sua escolha.

\section{REFERÊNCIAS}

1. ARAÚJO SM. A importância do pré-natal e assistência de enfermagem.Rev. Elet de Ciênc, 2013; Jul-Dez, 3(2): 6167.

2. CAUS ECM, et al. O processo de parir assistido pela enfermeira obstétrica no contexto hospitalar: significados para as parturientes. Esc Anna Nery, 2012; Mar 16(1):34-40.

3. WINCK DR, et al. Responsabilidade profissional na assistência ao parto: discursos de enfermeiras obstétricas. Rev. Esc. Anna Nery, 2012; 16(2): 53-6. 2012.

4. SODRÉ TM, et al. Necessidade de cuidado e desejo de participação no parto de gestantes residentes em Londrina - Paraná. Texto Contexto Enferm. 2010;19(3):452-60.

5. JAMAS MT, et al. Narrativas de mulheres sobre a assistência recebida em um centro de parto normal. Cad Saúde Publica, 2013; Dez 29(12): 2436-2446.

6. MINISTÉRIO DA SAÚDE (BR). Programa Humanização do Parto: Humanização no Pré-natal e nascimento. Brasília (DF): Ministério da Saúde; 2002.

7. VELHO MB, et al. Vivência do parto normal ou cesáreo: revisão integrativa sobre a percepção de mulheres. Texto Contexto Enferm, 2012 abr/jun; 21(2):458-66.

8. OLIVEIRA JUNIOR JC, SOUZA MKB. A humanização nos serviços da atenção básica de saúde: concepções de profissionais de saúde. Rev Enferm UFPE, 2013; Jun; 7(5):4370-7.

9. VELASQUE EAG, et al. O Enfermeiro No Processo Parir/Nascer: Estratégias de Cuidados E Humanização Do Parto.Rev. Enferm. UFSM, Santa Maria, 2011; Jun- Abr, 1(1) :80-87.

10. BRASIL. Ministério da Saúde. Secretaria de Assistência a Saúde. Departamento de Ações Programáticas Estratégicas. Portaria n. 1.459 , de 24 de junho de 2011. Institui, no âmbito do Sistema Único de Saúde (SUS) a Rede Cegonha. Diário Oficial da União, Brasília: Ministério da Saúde, 2011.

11. GONÇALVES R, et al. Vivenciado o cuidado no contexto de uma casa de parto: o olhar das usuárias. Rev. Esc. Enf. Usp, 2011, 45(1): 62-70.

12. WINCK DR, BRUGGEMANNI OM. Responsabilidade legal do enfermeiro em obstetrícia. Rev. Brasil. Enf, 2010; 63(.3): 464-69.

13. FRELLO AT, et al. Cuidado e conforto no parto: estudos na enfermagem brasileira. Rev. Ba de Enf, Salvador, 2012; 25(2): 8. 2012.

14. PRATA KS, et al. Acompanhante no centro obstétrico: significado para a equipe de enfermagem. Rev. Baiana de Enf, Salvador, 2013, 25(3).

15. FERREIRA LA, et al. A Expectativa Das Gestantes Em Relação Ao Parto.Rev. Pesq.Cuid. Fundam, Rio de Janeiro, 2013, Abr- Jun, 5(2): 3692-3697.

16. DEMARCHI R, et al. Percepção De Gestantes E Puérperas Prímiparas Sobre Maternidade. Rev. Enferm. UFPE, Recife, 2017; Jul, 11(2): 2663-2673.

17. MOUTA RJO, PROGIANTI JM. Estratégias de Luta das Enfermeiras da Maternidade Leila Diniz Para Implantação De Um Modelo Humanizado De Assistência Ao Parto. Text. Contex.Enferm, Florianópolis, 2009; Out-Dez, 18(4): 731-740.

18. FRANCISCO BS, et al. Percepções dos pais sobre suas vivencias como acompanhantes durante o parto e nascimento. Rev. Min. Enferm, Belo Horinzonte, 2015; Jul- Set,19 (3): 567-575.

19. LEAS RE, CIFUENTES DJ. Parto Humanizado: Contribuições Do Enfermeiro Obstetra Rev.Cienc. Cidadania, Santa Catarina, 2016, 2(1).

20. OLIVEIRA JDG, et al. Percepção De Enfermeiros Obstetras Na Assistência À Parturiente. Rev. Enferm. UFPE, Recife, 2016, Out,10(10): 3868-3875.

21. CARVALHO VF, et al. Direitos das parturientes: conhecimento da adolescente e acompanhante. Saúde. Soc, São Paulo, 2014; Jul, 23(2): 572-581. 
22. ANDRADE LO, et al. Práticas dos profissionais de enfermagem diante do parto humanizado, Rev enferm UFPE, Recife, 11(Supl. 6):2576-85, jun., 2017.

23. VELASQUE EAG; Pradebon, VM, Cabral, FB et al. O Enfermeiro No Processo Parir/Nascer: Estratégias de Cuidados E Humanização Do Parto.Rev. Enferm. UFSM, Santa Maria, 2011; Jun- Abr, 1(1) :80-87.

24. FRIGO J, et al. Assistência de Enfermagem a Perspectiva da Mulher no Trabalho de Parto e Parto.Cogitare. Enferm, Curitiba, 2013, Out- Dez, 18(4): 761-766.

25. VERSIANE CC, et al. Significado de parto humanizado para gestantes. J.Res. Fundam. Care, São Paulo, 2015; Jan- Mar, 7(1): 1927-1935.

26. BARROS TCX, et al. Assistência À Mulher Para A Humanização Do Parto E Nascimento. Rev. Enferm. UFPE, Recife, 2017; Fev, 12(2): 554-558.

27. MEdeiRos A. A Casa de Parto David Capistrano Filho pelas lentes de uma fotógrafa. História, Ciências, Saúde Manguinhos, Rio de Janeiro, 2018; Out- Dez, 25(4):1171-1183. 